\title{
Correction to: Multisensory Processing in the Auditory Cortex
}

Andrew J. King, Amy Hammond-Kenny, and Fernando R. Nodal

\section{Correction to:}

Chapter 6 in: A. K. C. Lee et al. (eds.), Multisensory Processes, Springer Handbook of Auditory Research 68, https://doi.org/10.1007/978-3-030-10461-0_6

This chapter was previously published non-open access. It has now been changed to open access under a CC BY 4.0 license and the copyright holder has been updated to "The Author(s)". The book has also been updated with these changes. 